\title{
The Influence Of Commitment To Project Objectives In Information Technology (IT) Projects
}

Melinda L. Korzaan, Middle Tennessee State University, USA

\begin{abstract}
Managing successful Information Technology (IT) projects remains a challenging and perplexing ambition in today's complex IT environment where project deliverables continue to be brought in behind schedule, over budget, and with less functionality than originally planned. This study delves into goal commitment theory to investigate the potential role of commitment to project objectives in improving the performance of IT projects. The following two questions are considered in this research: (1) How does commitment influence perceptions of project performance, and (2) What key factors predict commitment? Survey responses were collected from professionals currently involved in IT projects and data was analyzed using structural equation modeling. Results indicate that commitment to project objectives has a positive influence on perceptions of project performance both directly and indirectly through individuals' propensity to report project status information. Time pressure in the project was found to have a negative influence on commitment to project objectives, while perceptions of personal investment had a positive effect on commitment to project objectives. Time pressure also had a positive influence on perceptions of personal investment and a negative influence on perceptions of project performance. Implications for research and practice are discussed.
\end{abstract}

Keywords: Systems Development, Project Management, Goal Commitment, System Success, Goal Theory

\section{INTRODUCTION}

mproving the management and overall performance of Information Technology (IT) projects is a timeless goal that has captured the interest of practitioners and academicians alike. Research topics related to the management of IT projects and improving outcomes in terms of project objectives (e.g. budget, schedule, and functionality) have remained relevant and important over the course of decades (Barki, Rivard, \& Talbot, 2001). The relevance of IT project management is in part due to the predominately high failure rates of technology projects. "IT projects have an unenviable reputation for their high failure rate. Successful management of IT projects in terms of meeting cost, time, and functionality targets continues to be an elusive achievement" (Taylor, 2006, p. 49). Therefore, improving IT project performance remains at the forefront of research agendas. One aspect of project management that has been identified as an early warning sign of pending IT project failure is the lack of team commitment to project outcome goals (e.g. scope and schedule) (Kappelman, McKeeman, \& Zhang, 2006). This research looks more closely at the concept of project team commitment to outcome objectives by drawing from goal commitment theory in order to investigate theoretical underpinnings of commitment and how it relates to improving IT project performance. This study contributes to the existing project management body of knowledge by proposing and testing a theoretical model to help explain and predict project performance by incorporating goal theory with project management theory to better explain and predict overall project performance. Insight is gleaned from this model into how goal commitment theory can help project managers be better equipped to manage the IT project environment and motivate team members to improve overall project performance. This research is exploratory in nature and takes an initial look into the role of team member commitment in improving the management of IT projects. The research questions addressed in this study are: (1) How does commitment influence perceptions of project performance, and (2) What key factors predict commitment? 


\section{LITERATURE REVIEW AND HYPOTHESES}

\section{Commitment to Project Objectives}

Although goal theory has historically been a solid theoretical underpinning for predicting performance in a variety of situations (Lock, Latham, \& Erez , 1988), it has not received a significant amount of attention in the context of IT projects. However, studies that have been conducted in this area have shown significant results. For example, Abdel-Hamid, Sengupta, \& Swett (1999) found that cost/schedule goals led to projects with overall lower costs and that quality/schedule goals led to overall higher quality. Such positive initial results indicate a promising backdrop for researchers to consider when working towards developing theoretical and practical models for improving the performance of IT projects. Therefore, goal theory warrants closer consideration. This study draws form goal theory to investigate specifically the role of goal commitment in project performance. Goal commitment is defined as "one's attachment to or determination to reach a goal, regardless of the goal's origin" (Locke et al., 1988, p. 24). An important aspiration in the context of an IT project is to successfully complete the project in terms of adhering to time, budget, and functionality goals (Chou \& Yeh, 2007). Prevalent determinants of IT project success include the project being completed on time, within budget, with required specifications, and with the final product being of acceptable quality (Andersen, Buchall, Jessen, \& Money, 2006). Therefore, for this study, commitment will be measured in terms of the degree to which individual project team members are committed to the budget, schedule, functionality, and quality objectives of a project in which they are currently involved. In other words, commitment in this study is evaluated by the degree team members are attached to or determined to reach the budget, time, functionality, and quality goals of their IT project.

It is proposed that commitment to project outcome goals will have a positive influence on project performance. Goal theory literature has consistently affirmed that commitment and performance are positively linked (Lock, et al., 1988). Furthermore, Andersen et al. (2006) found a significant, positive relationship between project commitment and project success in terms of meeting time and budget objectives. However, Andersen et al. (2006) investigated an aggregate of projects varying in type and size. This study is distinguished from Andersen et al.'s work by incorporating additional psychological variables into a theoretical model and investigating the connection between commitment and project performance in the specific context of IT projects. Because extant goal theory establishes a connection between commitment and performance and because a positive relationship between commitment and performance was found by Andersen et al. in the context of projects in general, it is also believed that a positive relationship will be found between commitment and project performance in the context of an IT project.

H1: Commitment to project objectives will be positively related to perceptions of project performance.

A potential mechanism by which commitment may contribute to project performance is through its influence on individuals' inclinations to communicate or report important project status information. A key element in preventing project failure is to accurately report the status of the project so that warning signs of impending disaster can be identified and addressed before a project becomes another failure statistic. "Information systems project failures typically exhibit ample warning signs of impending failure, but for reasons that are not well understood, these warning signs are frequently ignored" (Cuellar, Keil, \& Johnson, 2006, p.76). The tendency of individuals to remain silent about a project's status has been likened to the mum effect, in which individuals are reluctant to relay unpleasant information (Smith, Keil, \& Depledge, 2001). However, individuals who are committed to the objectives of a project may be more inclined to report information about a project, regardless of whether the information is positive or negative, if they believed the information is important for keeping the project performance on track. According to an experiment in Abdel-Hamid et al. (1999), individuals who were more committed to a goal were more likely to make decisions to bring about the successful completion of the goal. Therefore, individuals who are committed to meeting project objectives may be more inclined to make decisions to share information about the project status, even if it means relaying "bad news", in order for necessary actions to be taken to keep the project on course and facilitate meeting the key project schedule, budget, functionality, and quality objectives. 
H2: Commitment to project objectives will be positively related to an inclination to report project information.

Additionally, if team members are more likely to openly communicate and discuss project information, then it is reasonable to expect the overall performance of the project to be improved. Theory substantiates that a reluctance to report negative project information inhibits the readiness of an organization to deal with potential problems and increases the impact of failure (Smith et al., 2001). If withholding pertinent information increases the impact of failure, then the reverse of this statement is also logical in that the more willing individuals are to report project status information then the more likely problems will be addressed while they are still manageable and ultimately the project performance will be improved.

H3: An inclination to report project information will be positively related to perceptions of project success.

\section{Personal Investment}

A sense of personal investment in a project represents an individual's internal investment of time, effort, and energy (Taylor \& Pierce, 1999). Personal investment in a project may invoke a sense of loss of internal resources and subsequently represent a "psychological" sunk cost that may increase individuals' commitment to a project, much in a similar manner as a loss of financial investment intensifies the escalation of commitment (Brockner, 1992). In addition, Allen and Meyer (1990) proposed personal investment as an antecedent to organizational continuance commitment in the organizational literature. Therefore, it is proposed that the more individuals have personally invested in a project, the more intense their commitment.

H4: Personal Investment will be positively related to commitment to project objectives.

\section{Time Pressure}

Perceptions of time pressure or time urgency while working on an IT project occurs when there is a sense of obligated urgency to complete something (e.g. a task) (Park, Im, \& Keil, 2008). This sense of urgency may be felt due to the degree to which stakeholder(s) demand the immediacy of attention (Park et al., 2008). As a result, this demand for immediacy of attention is liable to invoke feelings of stress and pressure as an individual grabs another cup of coffee for the energy necessary to complete a task or fulfill a request within an unreasonable timeframe. This intense expenditure of energy and effort within a short period of time will in turn likely increase an individual's perceptions of expending their overall personal investment of effort, time, and energy in the project.

H5: Time pressure will be positively related to personal investment.

Another aspect of time pressure is the feeling of being too rushed or hurried to analyze and evaluate information about a project (Brockner, 1992). This characteristic of not having enough time to properly analyze a situation before making a decision is what Perlow, Okhuysen, \& Prepenning (2002) identifies as a "speed trap". When caught in a "speed trap," individuals just react, and make a quick decision instead of taking the time to make an informed decision. Because in speed traps there is not enough time to evaluate a course of action or evaluate a decision's potential impact on project outcomes, the plan of action itself becomes the goal target instead of project objectives (e.g. time, budget, functionality, and quality) being the key goal targets. In other words, taking the fastest course of action ousts project objectives from their position as goal targets and the course of action itself becomes the primary goal target. Making a fast decision becomes the goal and the goal is to make a fast decision, there is no time to focus on project objectives as a goal. Therefore, because the individual's attention and commitment is refocused on making a fast decision, their commitment to overall project objectives may be diminished. Furthermore, a sense of time urgency may indicate a slippage in the project schedule. According to Park et al. (2008), a sense of time urgency is usually inspired by an external source, such as a time schedule. If an individual experiences a sense of time urgency because he/she sees that the schedule is slipping, then confidence may be lost in the ability to actually meet project objectives (e.g. it may be realized that it is impossible for the project to be completed on schedule). Therefore, commitment to project objectives may decline simply due to the realization that 
the objectives cannot be attained. Due to these aforementioned reasons, it is believed that an increased sense of time pressure or time urgency will lead to a decrease in commitment to project objectives.

H6: Time pressure will be negatively related to commitment to project performance.

Running behind schedule is a prevalent problem in IT projects. According to the $10^{\text {th }}$ edition of the CHAOS report, $51 \%$ of projects are challenged in meeting their original project estimates in terms of schedule, cost, or functionality (Henry, McCray, Purvis, \& Roberts, 2007). When a project is struggling in one of these areas, a reaction from team members may be to experience a sense of urgency in a frantic attempt to catch up and compensate for the slipping schedule, escalating cost, and/or deficiency in functionality. However, along with this sense of urgency to recoup losses, there is also likely to be a keen awareness that these slipping estimates are indications of a poorly performing project potentially on its way to failure. Therefore, it is proposed that more time pressure experienced in the project, the less likely the project is to be perceived as performing well.

H7: Time pressure will be negatively related to perceived project performance.

\section{METHOD}

Data was gathered via an online survey from a variety of individuals directly involved in IT development projects. Because this study focuses on the role of commitment at the individual level of analysis, it was important to survey individual project team members as the targeted sample. It is also important to target this same in order to expand the body of knowledge in the IT project literature. Studies often survey single informants on projects such as an IT auditor (Keil, Mann, \& Rai, 2000) or a primary decision maker from upper management (Keil \& Montealegre, 2000). Studying individual team members adds an important perspective in the realm of IT project management because these individuals are the ones most closely involved with the project (Keil \& Robey, 1999). Also, project team members have an influence on the information provided on project status reports (Snow \& Keil, 2002), and consequently are likely to have a key role in swaying the decisions of project leaders and even members of upper management. Therefore, the targeted sample was chosen to capture commitment specifically at the individual team member level of analysis and to enhance the existing body of literature by providing a unique perspective of projects from the team vantage point rather than a managerial vantage point. Measurement items on the survey were adapted from existing literature, and are provided in Appendix A. The Anderson and Gerbing (1988) two-step approach was used for analyzing the data. First, the validity and reliability of the construct measures were analyzed, and then the theoretical model was evaluated using Structural Equation Modeling (SEM) with AMOS.

\section{RESULTS}

The sample collected totaled 232 responses and was comprised demographically of $59.9 \%$ males and $40.1 \%$ females. The average participant was between 40 and 49 years old $(44.4 \%)$, had on average 9.92 years IT work experience, earned a four-year college degree (59.9\%), and had been employed at their current organization for 9.8 years. During the assessment of validity and reliability, all factor loadings were large (>.5) and significant except for one. The first item on the perceived project performance construct (P1), which referred to project costs, had a factor loading of .39. The other items for perceived project performance pertained to the project schedule, quality, and overall success. Because the respondents in the survey were predominately individuals who did not have decision-making power over the costs of the project, it is reasonable to conclude that they react to "costs" as a determinant of project success differently than someone who has the primary responsibility over budget decisions. Another reason the item did not load highly on the construct could be because individuals working directly on the functionality of a project may not be completely aware of how the project is performing in terms of costs; whereas they are more likely to be cognizant of scheduled deadlines. Furthermore, since they are closely working on the functionality of a project, they are probably more likely to be tuned into the quality of the functionality they are developing. Overall, cost is most likely the performance measure that individual project team members are less informed about and therefore it is deemed appropriate to drop the cost item for perceived project performance. Aside from the one item, all other validity and reliability measures proved to be sound with the composite reliability 
values $>.80$ and average variance extracted values $>.50$. Validity and reliability results, along with factor loadings, are provided in Table 1.

All seven of the hypotheses were supported and the final resultant model is shown in Figure 1. Commitment to project objectives had a significant and positive effect on both perceived project performance and inclination to report project information. Perceptions of time pressure were positively related to perceptions of personal investment and related negatively to both commitment to project objectives and perceptions of project performance. Perceptions of personal investment were positively related to commitment to project objectives. The R-squares indicate that the model explains $35 \%$ of the variance in perceived project performance, $25 \%$ of the variance in commitment to project objectives, and $6 \%$ of inclination to report project information. Overall model fit is good, with model fit indices displayed in Table 2.

Table 1: Factor Loadings, Composite Reliability, and Average Variance Extracted

\begin{tabular}{|c|c|c|c|}
\hline $\begin{array}{c}\text { Construct/ } \\
\text { Item }\end{array}$ & $\begin{array}{c}\text { Factor } \\
\text { Loading }\end{array}$ & $\begin{array}{l}\text { Composite } \\
\text { Reliability }\end{array}$ & $\begin{array}{c}\text { Average } \\
\text { Variance Extracted }\end{array}$ \\
\hline Perceived Project Performance $(\mathrm{P})$ & & .84 & .65 \\
\hline P1 (removed, factor loading was .39) & & & \\
\hline $\mathrm{P} 2$ & .522 & & \\
\hline P3 & .888 & & \\
\hline P4 & .948 & & \\
\hline Inclination to Report Project Information (IRPI) & & .86 & .76 \\
\hline IRPI1 & .999 & & \\
\hline IRPI2 & .721 & & \\
\hline Commitment to Project Objectives (CPO) & & .95 & .72 \\
\hline $\mathrm{CPO} 1$ & .935 & & \\
\hline $\mathrm{CPO} 2$ & .890 & & \\
\hline $\mathrm{CPO} 3$ & .843 & & \\
\hline CPO4 & .795 & & \\
\hline CPO5 & .902 & & \\
\hline CPO6 & .864 & & \\
\hline $\mathrm{CPO} 7$ & .751 & & \\
\hline CPO8 & .780 & & \\
\hline Time Pressure (TP) & & .88 & .73 \\
\hline TP1 & .890 & & \\
\hline TP2 & .992 & & \\
\hline TP3 & .612 & & \\
\hline Personal Investment (PI) & & .96 & .86 \\
\hline PI1 & .795 & & \\
\hline PI2 & .981 & & \\
\hline PI3 & .988 & & \\
\hline PI4 & .937 & & \\
\hline
\end{tabular}


Figure 1: Final Model

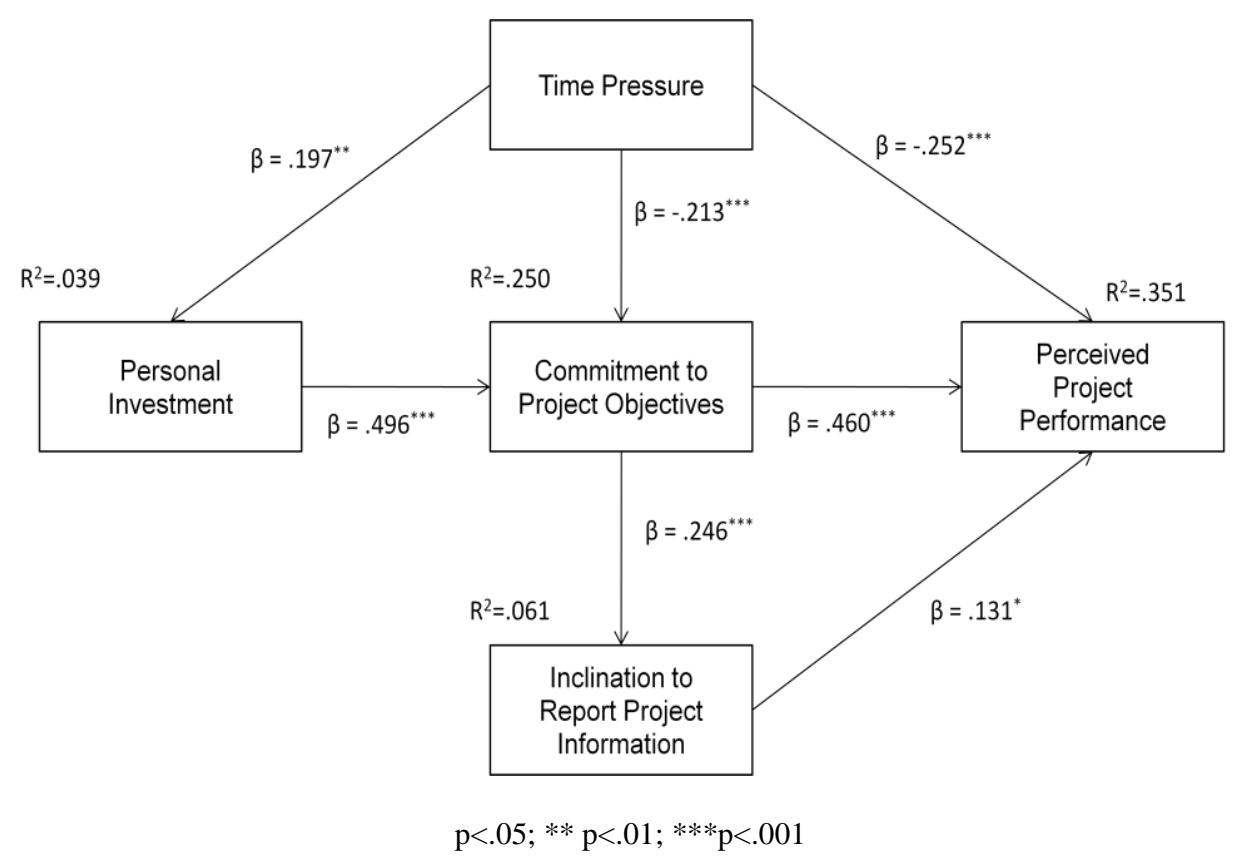

Table 2: Model Fit

\begin{tabular}{|l|c|c|c|c|c|c|}
\hline \multicolumn{1}{|c|}{ Fit Measures } & RMSEA & GFI & AGFI & RFI & CFI & Evaluation of Fit \\
\hline Thresholds & $<.10$ & $>=.90$ & $>=.80$ & $>=.90$ & $>=.90$ & \\
\hline Model & .054 & .99 & .96 & .92 & .99 & Good \\
\hline
\end{tabular}

\section{DISCUSSION}

This research offers a significant contribution to both theory and practice. For academicians, this study fills a gap in the literature by incorporating goal commitment theory within the stream of IT project management. The resultant model explains a decent amount of variance in both perceptions of project performance (35\%) and commitment to project objectives (25\%). Also, knowledge in the domain of goal theory has been extended by introducing personal investment, time pressure, and inclinations to report information within the context of goal commitment.

For practitioners, this study provides a valuable insight into the role of commitment in relation to project performance and individuals' inclination to communicate project status information. Results indicate that individual team members' commitment to time, budget, functionality, and quality objectives has a positive influence on both individuals' inclinations to report project status information as well as perceptions of project performance. Therefore it is very important for project managers to set realistic project objectives and communicate those objectives clearly to team members. They also may want to take the measurement items from the commitment to project objectives construct provided in this study and administer it to project team members as a gauge of the degree of commitment that exists within the team. If commitment is low, then it is recommended that mangers take steps to bolster commitment. It is suggested that managers take into consideration the helpful mechanisms, based in goal theory, which may either directly or indirectly enhance goal commitment. Some examples for managers to consider include making project goal objectives public knowledge, implementing reward structures, allowing team members to participate in setting objectives, setting realistic and attainable objectives, and simply being supportive of the team (e.g. listen to their opinions) (Hollenbeck \& Klein,1987). Another important consideration for project managers revealed from the model is that the total effect of time pressure on both commitment and project performance is negative. Taking into consideration both direct and indirect effects, time pressure has a total effect 
of -.115 on commitment to project objectives and a total effect of -.270 on perceptions of project performance. This is important for project managers because it shows that whenever project team members experience a time crunch, whether that time crunch is due to unrealistic time schedules or due to unexpected problems, there is an overall negative impact on both commitment and perceived project performance. Therefore, whatever managers can to do alleviate stress from time pressure is critical. One thing managers should consider is the importance of accurate schedule estimates. Other sources have emphasized the costliness of unrealistic project schedules (Michalak, 1997) and this study has revealed yet another reason for accuracy in estimating project schedules. Also, mechanisms and procedures need to be implemented so that team members know how to react whenever unexpected events occur that steer the project off schedule. With processes and procedures in place to handle unexpected events, a sense of time pressure may be attenuated. It is recommended that project managers also perform thorough risk analysis on their projects and even attend risk management training if necessary.

\section{LIMITATIONS AND FUTURE RESEARCH}

A limitation of this study is the use of perceptual measures for project performance. Although such measures are subject to bias, prior studies have set a precedence for using subjective project performance information (Standing, Guilfoyle \& Love, 2006; Barki \& Hartwick, 2001). While the benefit in using subjective information has been established, it is still recommended that future studies add to this body of knowledge by using objective measures of project performance (e.g. actual schedule, budget, and quality measures). Furthermore, while structural equation modeling was used as the statistical method, the data was still collected at one point in time. Therefore, future research needs to be conducted in order to confirm the causal relationships in the model through designing controlled experiments. Furthermore, future research needs to delve more deeply into goal theory to develop a more comprehensive model of goal commitment in the context of project management as well as explore more deeply the role of time urgency, personal investment, and inclinations to report project information in the context of improving the performance of IT projects.

\section{CONCLUSION}

This study provides a preliminary and exploratory investigation into the application of goal theory in an IT project management environment. Results indicate that individual team members' commitment to time, budget, functionality, and quality objectives has a positive influence on both individuals' inclinations to report project status information and perceptions of project performance. Also, the more individuals feel they have invested their own time, energy, and effort into a project, the stronger their commitment becomes to project objectives. The research also found a positive relationship between perceptions of time pressure and perceptions of personal investment, as well as a negative relationship between perceptions of time pressure and both commitment and project performance. The overall effect of time urgency on project performance was negative. Therefore, project managers need to be especially sensitive to unrealistic time constraints and should guard against an environment that promotes stress due to an overly rushed development environment. Overall, this study is an initial step to fill a gap in the literature by incorporating goal theory with project management to develop and test a theoretical model.

\section{AUTHOR INFORMATION}

Melinda Korzaan is an Assistant Professor of Computer Information Systems at Middle Tennessee State University. She completed a Ph.D. in Business Administration from The University of Arkansas in 2004. She teaches courses in Advanced Web-Enabled Application Development, Information Systems Management and Applications, and IT Project Risk Assessment and Control. Her research interests include IT project management, escalation of commitment, and information privacy.

\section{REFERENCES}

1. Abdel-Hamid, T.K., Sengupta, K., \& Swett, C. (1999). The impact of goals on software project management: An empirical investigation. MIS Quarterly, 23(4), 531-555.

2. Allen, N. J. and Meyer, J. P. (1990). The measurement and antecedents of affective, continuance, and normative commitment to the organization. Journal of Occupational Psychology, 63, 1-18. 
3. Andersen, E.S., Birchall, D., Jessen, S.A., \& Money, A.H. (2006). Exploring project success. Journal of Management, 1(2), 127-147.

4. Anderson, J. C. \& Gerbing, D. W. (1988). Structural Equation Modeling in Practice: A Review and Recommended Two-Step Approach. Psychological Bulletin, 103(3), 411.

5. Barki, H., \& Hartwick, J. (2001). Interpersonal conflict and its management in information systems development. MIS Quarterly, 25(2), 195-228.

6. Barki, H., Rivard, S., \& Talbot, J. (2001). An integrative contingency model of software project risk management. Journal of Management Information Systems, 17(4), 37-69.

7. Brockner, J. (1992). The escalation of commitment to a failing course of action: Toward theoretical progress. Academy of Management Review, 17(10), 39-61.

8. Chou, H. \& Yeh, Y. (2007). Conflict, conflict management, and performance in ERP teams. Social Behavior and Personality, 35(8), 1035-1048.

9. Cuellar, M.J., Kiel, M. \& Johnson, R.D. (2006). The deaf effect response to bad news reporting in information systems projects. e-Service Journal, 5(1), 75 - 97.

10. Dholakia, U. M. and Bagozzi, R. P. (2002). Mustering motivation to enact decisions: How decision process characteristics influence goal realization. Journal of Behavioral Decision Making, 15, 167-188.

11. Henry, R. M., McCray, G. E., Purvis, R. L., \& Roberts, T. L. (2007). Exploiting organizational knowledge in developing IS project cost and schedule estimates: An empirical study. Information \& Management, 44, 598612 .

12. Hollenbeck, J. R. \& Klen, H.J. (1987). Goal commitment and the goal-setting process: Problems, prospects, and proposals for future research. Journal of Applied Psychology, 72(2), 212-220.

13. Kappelman, L.A., McKeeman, R., \& Zhang, L. (2006). Early warning signs of IT project failure: The dominant dozen. Information Systems Management, 23(4), 31-36.

14. Keil, M. (1995). Pulling the plug: Software project management and the problem of project escalation. MIS Quarterly, 19(4), 421-448.

15. Keil, M. and Montealegre, R. (2000). Cutting your losses: Extricating your organization when a big project goes awry. Sloan Management Review, 41(3), 55-68.

16. Keil, M., Mann, J., Rai, A. (2000). Why software projects escalate: An empirical analysis and test of four theoretical models. MIS Quarterly, 24(4), 631-665.

17. Keil, M. \& Robey, D. (1999). Turning around troubled software projects: An exploratory study of the deescalation of commitment to failing courses of action. Journal of Management Information Systems, 15(4), 6388.

18. Klein, H. J, Wesson, M. J., Hollenbeck, J. R., Wright, P. M., \& DeShon, R. P. (2001). The assessment of goal commitment: A measurement model meta-analysis. Organizational Behavior and Human Decision Processes, 85(1), 32-55.

19. Lee, C., Jamieson, L. F., \& Earley, P. C. (1996). Belief and fears and Type A behavior: Implications for academic performance and psychiatric health disorder symptoms. Journal of Organizational Behavior, 17, 151177 .

20. Lock, E.A, Latham, G.A., \& Erez, M. (1988). The determinants of goal commitment. The Academy of Management Review, 13(1), 23-39.

21. Michalak, C. F. (1997). The cost of chasing unrealistic project schedules. AACE International Transactions, PC.02, 269-275.

22. Park, C.W., Im, G., \& Keil, M. (2008). Overcoming the mum effect in IT project reporting: Impacts of fault responsibility and time urgency. Journal of the Association for Information Systems, 9(7), 409-431.

23. Perlow, L.S., Okhuysen, G.A., \& Prepenning, N.P. (2002). The speed trap: Exploring the relationship between decision making and temporal context. Academy of Management Journal, 45(5), 931-955.

24. Smith, J.H., Keil, M., \& Depledge, G. (2001). Keeping mum as the project goes under: Toward an explanatory model. Journal of Management Information Systems, 18(2), 189-227.

25. Snow, A.P. \& Keil,M. (2002). The challenge of accurate software project status reporting: A two-stage model incorporating status error and reporting bias. IEEE Transactions on Engineering Management, 49(4), 491-405.

26. Standing, C., Guilfoyle, A., Lin, C. \& Love, P.E.D. (2006). The attribution of success and failure in IT projects. Industrial Management \& Data Systems, 106(8), 1148-1165.

27. Taylor, H. (2006). Risk management and problem resolution strategies for IT projects: Prescription and practice. Project Management Journal, 37(5), 49-63.

28. Taylor, P.J. \& Pierce, J.L. (1999). Effects of introducing a performance management system on employees' subsequent attitude and effort. Public Personnel Management, 3(3), 432-452. 


\section{APPENDIX A - MEASUREMENT SCALES}

\section{Project Performance (Barki \& Hartwick, 2001)}

Regarding the current status of this project...

[P1] Compared to its estimated cost, this project is currently (over budget, under budget)*

[P2] Compared to its estimated schedule, the project is currently running (behind schedule, ahead of schedule)

[P3] In general, I think that the quality of this project so far to be (low quality, high quality)

[P4] Overall, I consider this project so far to be (unsuccessful, successful)

*Due to low factor loading $(<.50)$ the item $[\mathrm{P} 1]$ was dropped from the construct

\section{Commitment to Project Objectives (Klein et al., 2001)}

Consider your personal beliefs and feelings related to the project you are currently working on...

[CPO1] I am committed to completing this project on time.

[CPO2] It is important to me that this project is completed according to schedule.

[CPO3] I am committed to completing this project within budget.

[CPO4] It is important to me that this project is finished within budget.

[CPO5] I am committed to finishing every deliverable for this project.

[CPO6] It is important to me that all the required functionality is completed for this project.

[CPO7] I am committed to the quality of this project.

[CPO8] The quality of this project's outcome is important to me.

\section{Inclination to Report Project Information (Smith et al, 2001)}

Regarding the current status of this project...

[IRPI1] How likely would you be to go directly to upper management by yourself to discuss the status of this project?

[IRPI2] How likely would you be to try and persuade members of the development team to go to upper management and discuss as a group the status of this project?

\section{Time Pressure (Lee et al, 1996)}

While working on the project I often feel...

[TP1] I am pressed for time.

[TP2] Rushed to meet the deadline.

[TP3] There is not enough time to deal with any problems that might arise.

\section{Personal Investment (Keil 1995; Dholakia \& Bagozzi, 2002; Taylor \& Pierce, 1999)}

Consider your personal beliefs and feelings related to the project you are currently working on...

[PI1] I have worked particularly hard at doing a good job on this project.

[PI2] I have already spent a great deal of energy on this project.

[PI3] I have invested a considerable amount of effort on this project.

[PI4] I have put in a great deal of time on this project. 


\section{NOTES}

